\title{
4. 畏野旉碼眆地方の「力岩」について
}

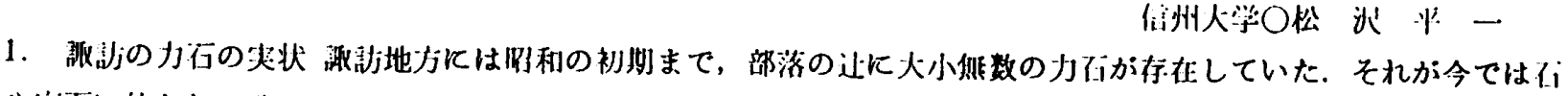

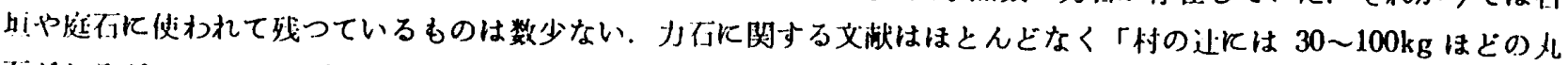

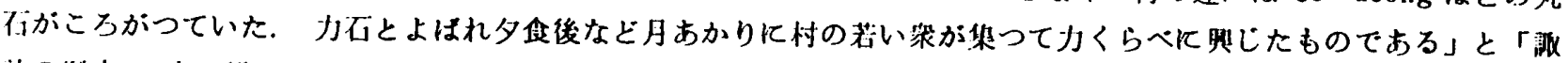

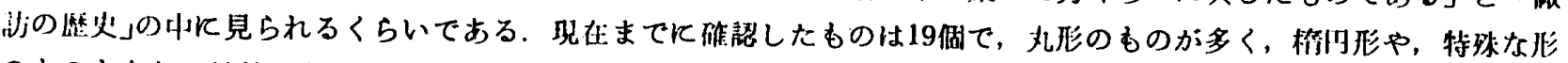

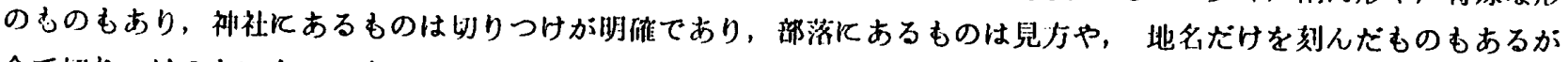
全て奶りつけのないものが多い.

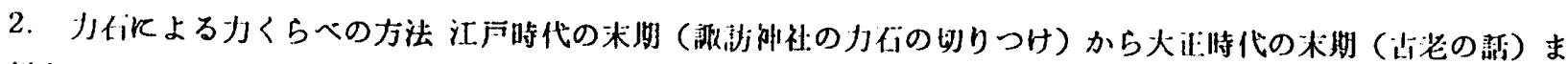

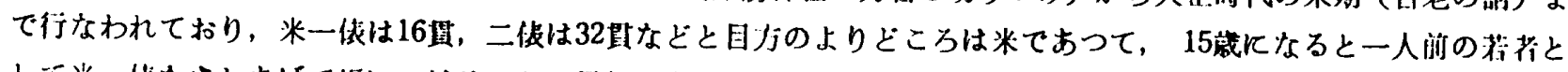

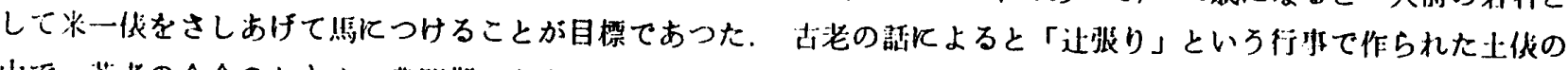

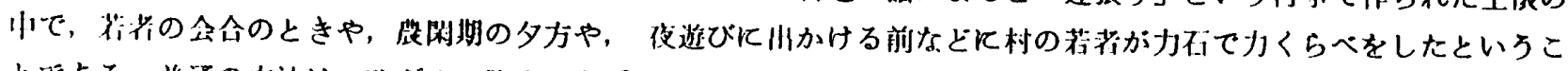

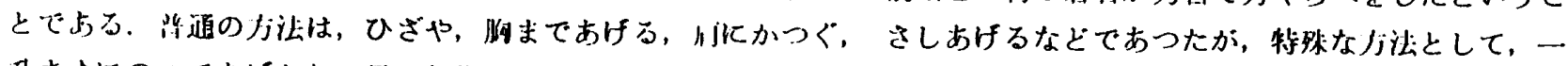

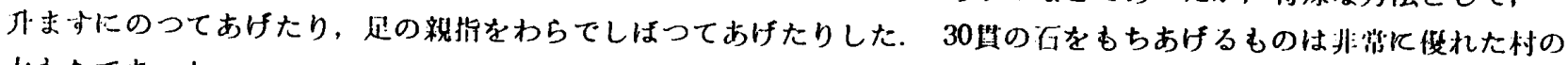
ノもちであつた。

\section{5. 埼玉県越谷市を中心とした力石の分布と琶是}

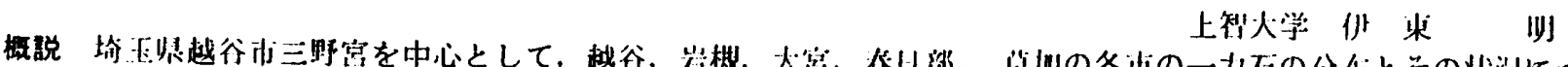
て調夜し洘察した。

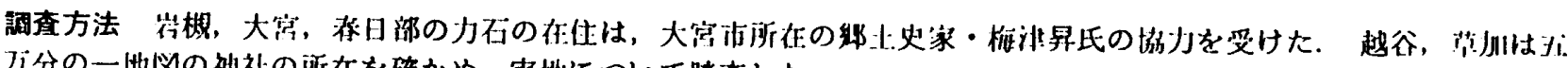

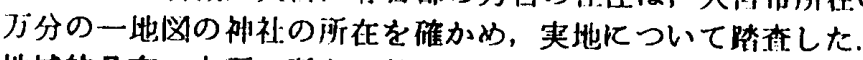

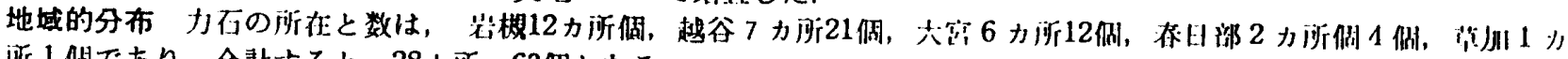

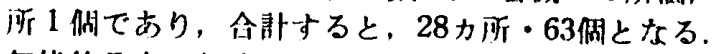

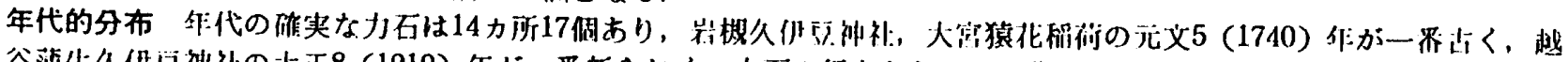

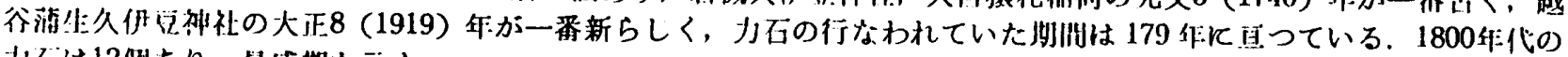
才仙12湖あり，㻭搵期を示与。

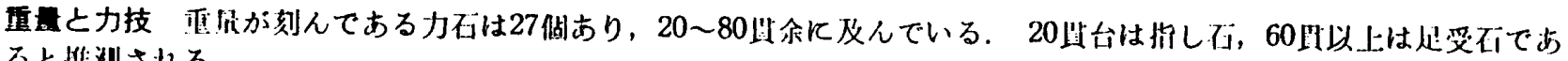
ると推测される。

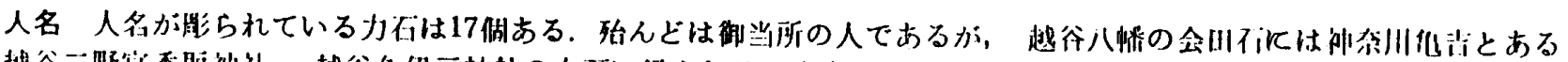

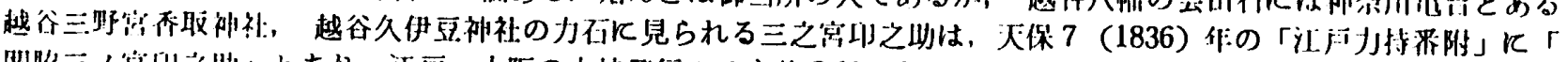

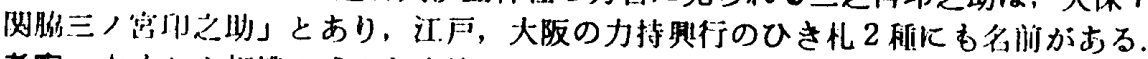

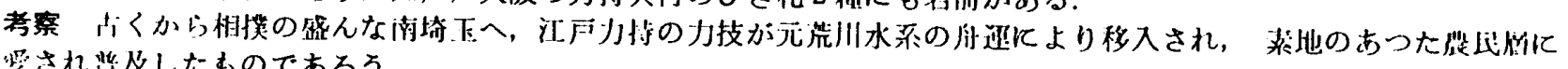
啰され治及したものであろろ。

\section{6. 三浦ヒロのダンス踰一大正期新教育を背景として一}

女子美術大学 四枝夕力子 お茶の水父子大学 汒木利子

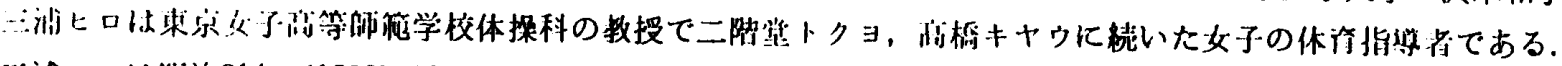

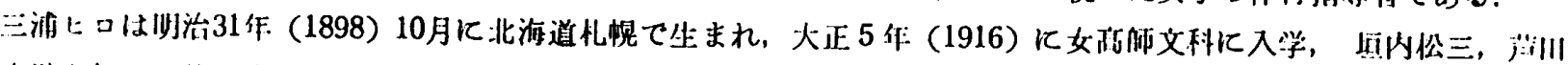

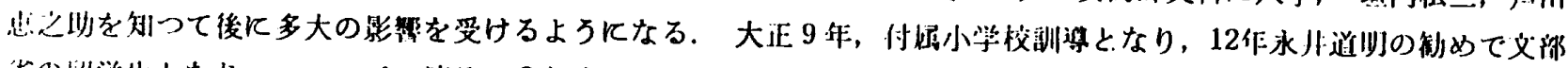

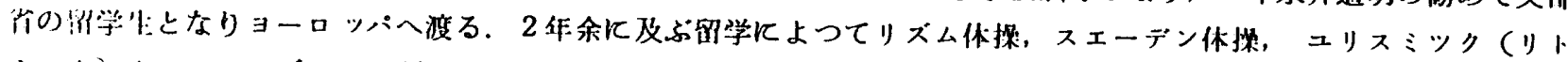

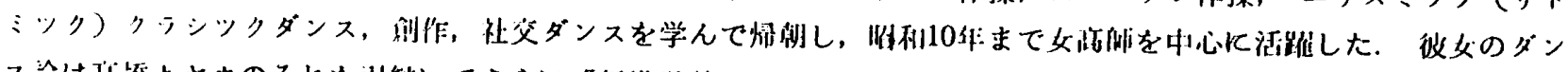

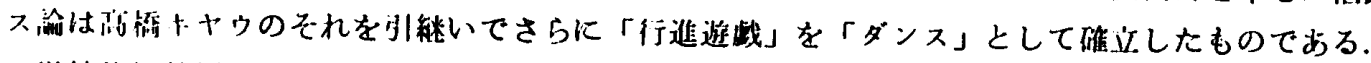

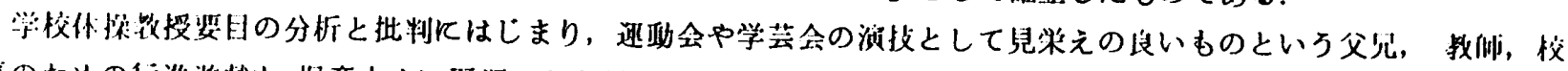

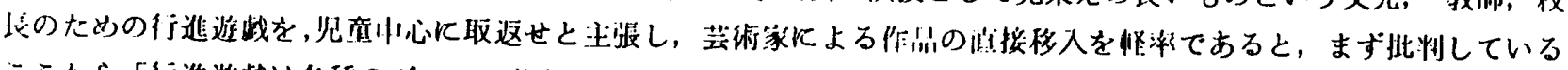

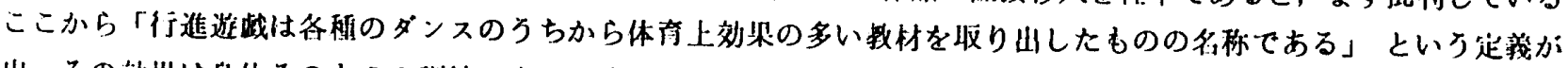

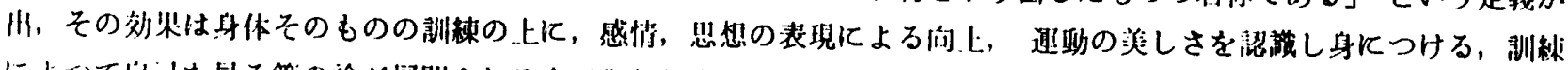

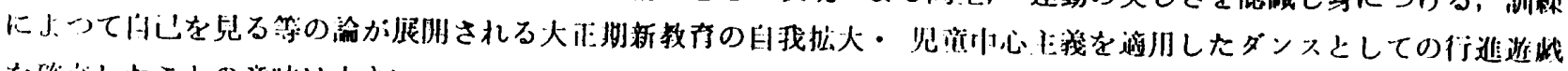

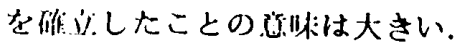

